\title{
Pattern of obstetrics complication among pregnant females admitted in a tertiary care centre in central India
}

\author{
Manik S. Shirpurkar ${ }^{1}$, Mamta K. Shewte ${ }^{2} *$ Prajkta G. Joshi $^{1}$ \\ ${ }^{1}$ Department of Obstetrics and Gynaecology, ${ }^{2}$ Department of Community Medicine, Chirayu Medical College and \\ Hospital, Bhopal-462030, M.P., India
}

Received: 08 January 2015

Revised: 18 February 2015

Accepted: 01 March 2015

\section{*Correspondence:}

Dr. Mamta K. Shewte,

E-mail: umeztochi@hotmail.com

Copyright: $\odot$ the author(s), publisher and licensee Medip Academy. This is an open-access article distributed under the terms of the Creative Commons Attribution Non-Commercial License, which permits unrestricted non-commercial use, distribution, and reproduction in any medium, provided the original work is properly cited.

\begin{abstract}
Background: About half a million women die every year of causes related to pregnancy and child birth. Complication can arise at any time during pregnancy; child birth and post natal period and in absence of intervention, there is a high feto - maternal morbidity and mortality. The aim was to study the pattern of obstetrics complication among antenatal patients coming to a tertiary care centre.

Methods: A cross sectional study was conducted among 102 antenatal women admitted in intensive care unit of our institute during July 2014 to November 2014. Data regarding maternal socio-demographic profile and antenatal profile was collected.

Results: Total 102 women included in the study. 95 (93\%) were registered and 7 were unregistered women. 88 $(86.4 \%)$ women had 3 or more antenatal visit, of which $3(2.9 \%)$ were unregistered women. $82(80.3 \%)$ women had blood $\mathrm{Hb} \%<11$; of which 7 (6.8\%) were unregistered women. Out of total 102 women, $64(62.7 \%)$ women were having complications related to abnormal labour; 34 (33.3\%) obstetrical disorder, 21 (20.5\%) hypertensive disorder. Because of multi-disciplinary team approach at our institute, no maternal mortality was reported among the antenatal women admitted during this period in our institute.

Conclusions: All women need access to antenatal care; institutional delivery and post- partum care. Complication arises at any time in absence of intervention. Multidisciplinary team approach along with intensive care specialist and anaesthesiologists can bring optimum care and thereby help in reducing maternal mortality.
\end{abstract}

Keywords: Antenatal care, Obstetric complication, Outcome of pregnancy, Registered pregnant women and unregistered pregnant women

\section{INTRODUCTION}

Pregnancy is an important stage in a woman's life. It is a period of expectant waiting and one that all women aspire to experience at least once in their lifetime. It is a fervent hope of all mothers-to-be to have a safe and healthy pregnancy. ${ }^{1}$ Pregnancy is a physiological state of stress on the body and by itself makes women prone to many disorders and diseases. This, coupled with the complications of pregnancy can have various severe deleterious effects on the health of the mother and the foetus. ${ }^{2,3}$ WHO report 2005 shows that one woman die of pregnancy and childbirth related complications every minute, i.e. more than half a million every year. ${ }^{4}$ While most pregnancies and births are uneventful, all pregnancies are at risk. Around 15\% of all pregnant women develop a potentially life-threatening complication that calls for skilled care and some will require a major obstetrical intervention to survive (WHO, 2000). ${ }^{5}$ In general, complications of pregnancy are the 
symptoms and problems that are associated with pregnancy. ${ }^{6}$ Of all maternal deaths, $80 \%$ can be potentially avoided by interventions during pregnancy, childbirth and the postpartum period, that are feasible in most countries. The common causes of maternal death include haemorrhage, hypertension, infection, obstructed labour and unsafe abortion. ${ }^{7}$ In tertiary care centre like ours, many women with obstetrics complications are referred not only from private clinics and hospitals but also from nearby villages, PHCS, sub centres, UHTCS. ${ }^{8}$ There are women who came for delivery and who had not taken any antenatal care. Complications can arise any time during pregnancy, child birth and post natal period and in absence of skilled intervention, there is a high feto-maternal morbidity and mortality. ${ }^{2}$ In India, data show that $70 \%$ of mothers, who had four or more antenatal check-ups, delivered in institutions compared with $7 \%$ for those who had no antenatal check-ups. ${ }^{9}$

Hence, the present study is conducted with objective of, to study the clinic -social profile, pattern of obstetrics complications, pregnancy outcome, and utilization of health services among antenatal patients coming to our institute.

\section{METHODS}

The present cross sectional study was carried out at Chirayu Medical College and Hospital, a Tertiary care centre at Bhopal, Madhya Pradesh in central India. Considering the high maternal mortality rate of the region, each pregnant women coming to our department are managed depending on level and number of complications in them. This mean that seriously compromised cases and patients with multiple complications were managed in intensive care unit. Other cases were treated intensively as, 'high risk' cases in labour room under full attention of obstetrician thoroughly. The total bed strength of our ICU is 49 beds which are shared between other specialties as medicine, surgery, nephrology, CVTS and general. The study was conducted during July 2014 to November 2014. Institutional ethical clearance was sought. Study subjects were all pregnant women admitted in intensive care unit at our institute and consenting to participate during study period.

During the study period 144 antenatal women's were admitted in ICU and 102 pregnant women gave consent to participate in study, so the data was collected from 102 pregnant women, using predesigned and pre-tested structured questionnaire. The questionnaire had two parts, first part had socio-demographic profile, obstetrics history, information regarding pregnancy registration and services availed during pregnancy. The second part of the questionnaire had questions regarding complication in present pregnancy; investigation done, services received in our hospital, delivery pattern, pregnancy outcome, birth weight of baby delivered.
The participation study subjects were on voluntary basis, written informed consent was obtained from study participants, anonymity and confidentiality was assured and emphasized. During data collection vital status of study subjects was assessed and if they were in the position to give interview, then only the data was collected by interview technique, which took 20 to 30 minutes for each.

The term 'Registered patient' was used for pregnant women who were registered at our institute, PHCS, UHCS, at Aganwadi or at any other private hospital. The unregistered patients were these who were not registered anywhere at all.

Analysis of 102 patients was done. Risk factors were identified among 43 pregnant women registered at our institute, but there correlation with complications will be analysed subsequently, as presently our objective is only to observe the pattern of complication. Pregnancy outcome; obstetrics disorder; hypertensive disorder, anaemia, heart disease; Rh-isoimmunisation, coagulation disorder, thyroid disorder, renal diseases etc.; transfusion of blood and blood products in registered and unregistered women were analyzed according to criteria given by Maternal Health Division, Department of Family Welfare, Ministry of Health and Family Welfare Government of India. ${ }^{10}$ For analysis of complications like abortion, ectopic pregnancy, intra-uterine growth retardation, antepartum haemorrhage, multifetal pregnancy, placenta previa, hydraminos, post term, intra uterine fetal death, gestational trophoblastic diseases, they were clubbed together under obstetrics disorder. ${ }^{11}$ The data entered in Microsoft excel 2007. All the continuous variable summarized using mean and SD while the categorical variables as percentage and proportion.

\section{RESULTS}

Total 144 pregnant women were admitted in ICU of our institute and 102 pregnant women gave consent to participate in study. So, analysis of data from 102 pregnant women was done. Out of total 102 pregnant women admitted in ICU of our institute 95 (93\%) pregnant women were registered and 7 (6.8\%) were unregistered. Out of 95 registered patients; 43 pregnant women were registered at our institute; 29 were registered at Aganwadi; 15 were registered at private hospital; 3 were registered both at Aganwadi and our institute; 5 were registered both at Aganwadi and some other private hospital. No statistical test was applied while seeing observation among registered and unregistered pregnant women. No comparison done between the two groups as number of unregistered pregnant women were very low as compared to registered pregnant women. Table 1 shows demographic profile of 
ANC women, maximum, $85(83.5 \%)$ pregnant women were in 20-29 age group, $111(10.7 \%)$ were in $30-34$ age group and $1(0.9 \%)$ was in 15-19 age group. $62(60.8 \%)$ pregnant women were of rural residence. Maximum, 56 $(54.9 \%)$ pregnant women were having primary education. $8(7.8 \%)$ were illiterate and $3(2.9 \%)$ were graduate and above. Table 2 shows antenatal care in present pregnancy, $85(89.9 \%)$ study subjects in registered pregnant women group and only $3(50.2 \%)$ study subjects in unregistered pregnant women group had more than 3 antenatal visit. $2(33.7 \%)$ study subjects in unregistered women group did not have any antenatal care visit. $6(85.7 \%)$ study subjects in unregistered women group and only 1 study subject in registered pregnant women group had taken iron-folic acid tablets for less than 100 days. $93(98 \%)$ of study subjects in registered pregnant women group had taken iron-folic acid tablet for 61-100 days. 94 (99\%) study subjects in registered pregnant women group had taken 2 doses of tetanus toxoid injection, while there was only 1(14.2\%) of unregistered pregnant women who had taken 2 doses of tetanus toxoid injection.

Table 1: Demographic profile of ANC women.

\begin{tabular}{|c|c|c|c|}
\hline Sr. No. & $\begin{array}{l}\text { Demographic } \\
\text { profile }\end{array}$ & $\begin{array}{l}\text { No. of ANC } \\
\text { women } \\
(\mathrm{N}=102)\end{array}$ & $\begin{array}{l}\text { No. of ANC } \\
\text { women }\end{array}$ \\
\hline 1. & $\begin{array}{l}\text { Registered } \\
\text { pregnancy }\end{array}$ & 95 & 93 \\
\hline 2. & \multicolumn{3}{|c|}{ Age group in years } \\
\hline & $15-19$ & 1 & 0.9 \\
\hline & $20-24$ & 50 & 49.2 \\
\hline & $25-29$ & 35 & 34.3 \\
\hline & $30-34$ & 11 & 10.7 \\
\hline & $35-39$ & 5 & 4.9 \\
\hline & $40-44$ & 0 & 0 \\
\hline \multirow[t]{3}{*}{3.} & \multicolumn{3}{|l|}{ Residence } \\
\hline & Urban & 40 & 39.2 \\
\hline & Rural & 62 & 60.8 \\
\hline \multirow[t]{7}{*}{4.} & \multicolumn{3}{|c|}{ Education status } \\
\hline & Illiterate & 8 & 7.8 \\
\hline & Primary & 56 & 54.9 \\
\hline & Middle & 17 & 16.9 \\
\hline & High school & 12 & 11.7 \\
\hline & Intermediate & 6 & 5.8 \\
\hline & $\begin{array}{l}\text { Graduate and } \\
\text { above }\end{array}$ & 3 & 2.9 \\
\hline
\end{tabular}

$5(71.4 \%)$ study subjects in unregistered pregnant women group had severe anaemia. 56 (58.9\%) study subjects in registered pregnant women group who had mild anaemia. $5(71.4 \%)$ study subjects in unregistered women group were $\mathrm{HBsAg}$ positive. None in registered pregnant women group were HBsAg positive. All the study subjects $(100 \%)$ in unregistered pregnant women group received blood transfusion when admitted at our institute while $10(10.5 \%)$ study subjects in registered pregnant women group received blood transfusion at our institute.

Table 2: Distribution of study subjects according to status of antenatal care in present pregnancy.

\begin{tabular}{|c|c|c|c|c|}
\hline $\begin{array}{l}\text { Sr. } \\
\text { No. }\end{array}$ & $\begin{array}{l}\text { Antenatal } \\
\text { care }\end{array}$ & $\begin{array}{l}\text { Registered } \\
(\mathrm{N}=95)\end{array}$ & $\begin{array}{l}\text { Not } \\
\text { registered }\end{array}$ & $\begin{array}{l}\text { Total } \\
(\mathrm{N}=102)\end{array}$ \\
\hline 1. & \multicolumn{4}{|c|}{ No. of ANC visit } \\
\hline & 0 & - & $2(33.7)$ & $2(1.9)$ \\
\hline & 1 & $2(1.9)$ & $1(1.9)$ & $3(2.9)$ \\
\hline & 2 & $8(7.9)$ & $1(6.8)$ & $9(8.8)$ \\
\hline & $\geq 3$ & $85(89.9)$ & $3(50.2)$ & $88(86.4)$ \\
\hline \multicolumn{5}{|c|}{ 2. IFA tables } \\
\hline & $<30$ days & $1(1)$ & $6(85.7)$ & $7(6.8)$ \\
\hline & 30-60 days & $1(1)$ & $1(14.3)$ & $2(1.9)$ \\
\hline & 61-100 days & $93(98)$ & $0(00)$ & $93(91.3)$ \\
\hline \multirow[t]{4}{*}{3.} & TT injection & & & \\
\hline & 0 & $0(0)$ & $5(85.7)$ & $5(4.9)$ \\
\hline & 1 & $1(1)$ & $1(14.2)$ & $2(0.9)$ \\
\hline & 2 & $94(99)$ & $1(14.2)$ & $95(93.1)$ \\
\hline \multirow[t]{5}{*}{4.} & $\mathbf{H b} \%$ & & & \\
\hline & $<7$ & $0.4(4.2)$ & $5(71.4)$ & $5(4.9)$ \\
\hline & $7.1-9$ & $15(15.7)$ & $2(28.6)$ & $17(16.6)$ \\
\hline & $9-11$ & $56(58.9)$ & $00(00)$ & $56(58.9)$ \\
\hline & $>11$ & $20(20.12)$ & $00(00)$ & $20(19.7)$ \\
\hline \multirow[t]{3}{*}{5.} & HBsAg & & & \\
\hline & Reactive & $00(00)$ & $5(71.4)$ & $5(4.9)$ \\
\hline & $\begin{array}{l}\text { Non- } \\
\text { Reactive }\end{array}$ & 95 (100) & $2(28.6)$ & $97(95.1)$ \\
\hline \multirow[t]{3}{*}{6.} & HIV I/II & & & \\
\hline & Reactive & $0(00)$ & $0(00)$ & $0(00)$ \\
\hline & $\begin{array}{l}\text { Non- } \\
\text { Reactive }\end{array}$ & $95(100)$ & $7(100)$ & $102(100)$ \\
\hline 7. & USG done & 87 (91.5) & $7(100)$ & $\begin{array}{l}94 \\
(92.10)\end{array}$ \\
\hline \multirow[t]{2}{*}{8.} & Blood transf & ion & & \\
\hline & Received & $10(10.5)$ & 7 (100) & $17(16.6)$ \\
\hline
\end{tabular}

Figures in parenthesis indicate percentages

Figure 1 shows complications in present pregnancy. 62 $(65.2 \%)$ study subjects in registered pregnant women group and $2(28.5 \%)$ study subjects in unregistered pregnant women group had abnormal labour. 31 (32.6\%) study subjects in registered pregnant women group had obstetrics disorder, $20(21.0 \%)$ study subjects in registered pregnant women group had hypertensive disorder. Other complications among study subjects were fever; hepatomegaly; ruptured uterus; epixtasis; hyperemesis gravidaram, abdominal pain and mental retardation. 

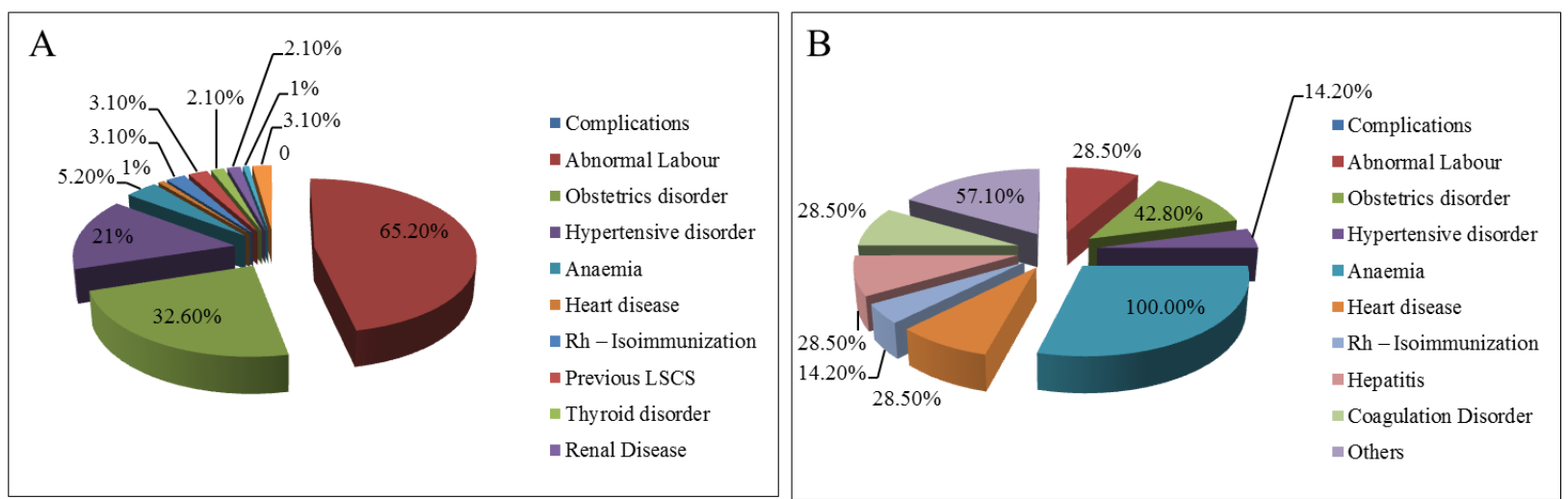

* Data are not mutually exclusive

Figure 1: Distribution of study subjects according to complications in present pregnancy (A) Complications*in registered pregnant women (B) Complications* in unregistered pregnant women.

Table 3: Distribution of study subjects according to outcome in present pregnancy.

\begin{tabular}{|c|c|c|c|c|}
\hline $\begin{array}{l}\text { Sr. } \\
\text { No. }\end{array}$ & Outcome & $\begin{array}{l}\text { Registere } \\
\text { d } \\
(\mathbf{N}=95)\end{array}$ & $\begin{array}{l}\text { Unregistered } \\
(\mathrm{N}=7)\end{array}$ & $\begin{array}{l}\text { Total } \\
(\mathrm{N}=102)\end{array}$ \\
\hline \multirow[t]{5}{*}{1.} & \multicolumn{4}{|l|}{ Gravida } \\
\hline & 1 & $46(48.5)$ & $4(57.3)$ & $\begin{array}{l}50 \\
(49.1)\end{array}$ \\
\hline & 2 & $26(27.3)$ & $2(28.5)$ & $\begin{array}{l}28 \\
(27.4)\end{array}$ \\
\hline & 3 & $14(14.7)$ & $1(14.2)$ & $\begin{array}{l}15 \\
(14.7)\end{array}$ \\
\hline & $\geq 4$ & $9(9.5)$ & $0(00)$ & $9(8.8)$ \\
\hline \multirow[t]{6}{*}{2.} & \multicolumn{4}{|c|}{ Term of pregnancy } \\
\hline & Full & $68(71.5)$ & $1(14.2)$ & $\begin{array}{l}69 \\
(67.7)\end{array}$ \\
\hline & Pre-term & $11(11.5)$ & $4(57.3)$ & $\begin{array}{l}15 \\
(14.7)\end{array}$ \\
\hline & Post-term & $9(9.5)$ & $0(0)$ & $9(8.8)$ \\
\hline & Abortion & $7(7.5)$ & $2(28.5)$ & $9(8.8)$ \\
\hline & Total & $95(100)$ & $7(100)$ & $\begin{array}{l}102 \\
(100)\end{array}$ \\
\hline \multirow[t]{6}{*}{3.} & \multicolumn{4}{|c|}{ Intervention for delivery } \\
\hline & $\begin{array}{l}\text { Normal } \\
\text { vaginal }\end{array}$ & $25(26.3)$ & $0(0)$ & $\begin{array}{l}25 \\
(24.6)\end{array}$ \\
\hline & $\begin{array}{l}\text { Assisted } \\
\text { vaginal }\end{array}$ & $2(2.2)$ & $1(14.2)$ & $3 *(2.9)$ \\
\hline & $\begin{array}{l}\text { Caesarean } \\
\text { section }\end{array}$ & $62(65.2)$ & $4(57.3)$ & $\begin{array}{l}66 \\
(64.7)\end{array}$ \\
\hline & Undelivered & $6(6.3)$ & $2(28.5)$ & $8(7.8)$ \\
\hline & Total & $95(100)$ & $7(100)$ & $\begin{array}{l}102 \\
(100)\end{array}$ \\
\hline \multirow[t]{6}{*}{4.} & \multicolumn{4}{|c|}{ Baby delivery } \\
\hline & Male & $48(50.5)$ & $1(14.2)$ & $49(48)$ \\
\hline & Female & $47(49.4)$ & $1(14.2)$ & $48(47)$ \\
\hline & Twins & $5(5.2)$ & $0(0)$ & $5(4.9)$ \\
\hline & Still birth & $2(2.1)$ & $1(14.2)$ & $3(2.9)$ \\
\hline & IUD & $0(0)$ & $2(28.5)$ & $2(1.9)$ \\
\hline
\end{tabular}

Figures in parenthesis indicate percentages. *Include 1 laparotomy
Table 3 shows outcome in present pregnancy, 50(49.1\%) of all study subjects were primigravida. Maximum, 46 $(48.5 \%)$ study subjects in registered pregnant women group were primigravida. $69(67.7 \%)$ of all study subjects were full term pregnant. 7 (7.5\%) study subjects in registered pregnant women group had abortion. 11 $(11.5 \%)$ study subjects in registered pregnant women group had preterm delivery as compared to 4 (57.3\%) study subjects in unregistered pregnant women group. Only, $25(26.3 \%)$ study subject in registered pregnant women had normal vaginal delivery. Maximum, 62 $(65.2 \%)$ study subjects in registered pregnant women group had caesarean section. $3(2.9 \%)$ of all study subjects had assisted vaginal delivery. 49 (48\%) of all study subjects delivered male child. $5(5.2 \%)$ were twins delivery among registered pregnant women group. 2 $(2.1 \%)$ were still birth among registered pregnant women group as compared to $2(28.5 \%)$ intra-uterine death among unregistered pregnant women group. 8 (7.8\%) study subjects, during study period were undelivered and were not followed up later on, as they took leave against medical advice (LAMA) because of their personal and socioeconomic reasons.

\section{DISCUSSION}

ANC refers to pregnancy-related health care, which is usually provided by a doctor, an Auxiliary Nurse Midwife (ANM), or another health professional. Ideally, antenatal care should monitor a pregnancy for signs of complications, detect and treat pre-existing and concurrent problems of pregnancy, and provide advice and counselling on preventive care, diet during pregnancy, delivery care, postnatal care and related issues. We analysed data among pregnant women with complication. 
In present study, none of the unregistered pregnant women had taken iron-folic acid for complete 100 days. The provision of IFA tablets to pregnant women to prevent nutritional anaemia forms an integral part of the safe motherhood services offered as part of reproductive and child health programme in India. The programme recommendation is that women consume 100 tablets of iron and folic acid during pregnancy. As per NFHS $-3^{12}$; overall, only $23 \%$ of women consumed IFA for at least 90 days. This percentage is universally low among all groups of women. Anaemia continues to be a major public health problem worldwide, particularly among females of reproductive age in developing country settings. The WHO estimates that $58 \%$ of pregnant women in developing counties are anaemic. According to NFHS-3, the prevalence of anaemia among pregnant women is higher $(59 \%)$ and the prevalence for mild (26.1); moderate $(31 \%)$ and severe $(2 \%)$ anaemia is greater among pregnant women. Ashwini $\mathrm{S}$ et al. ${ }^{1}$ observed (79.4\%) pregnant women were severely anaemic, (98.4\%) pregnant women had complete TT immunization. Verma V et al. ${ }^{13}$, Kore SJ et al. ${ }^{14}$ observed increased incidence of anaemia in teenage mother. Jat TR et al. ${ }^{15}$ observed that the use of maternal health services in Madhya Pradesh state remains low in comparison with many other Indian states. They observed that $(61.7 \%)$ of pregnant women received full antenatal care and $(49.8 \%)$ of pregnant women received skilled attendance at delivery.

In spite of the fact that most ministries of health in developing countries have policies to provide pregnant women with iron in a supplement form, maternal anaemia prevalence has not declined significantly where largescale programs have been evaluated. Despite $98 \%$ IFA supplementation among registered pregnant women, the $75 \%$ of women had anaemia; as compared to $100 \%$ women among unregistered group.

In present study, only $12(11.7 \%)$ of women were admitted for severe anaemia, $64(62.7 \%)$ of admitted pregnant women had abnormal labour, 34 (33.3\%) had obstetric disorder and $21(20.5 \%)$ had hypertensive disorder, which is comparable with Thaker $\mathrm{R}$ et al. ${ }^{2}$ who reported $61(27.8 \%)$ of complications related to labour, $41(18.7 \%)$ related hypertensive disorders, $12(5.4 \%)$ problems related to obstetric haemorrhage, among unregistered pregnant women. Gogoi et al. ${ }^{3}$ reported $(56 \%)$ had obstructed labour at time of delivery, $(55 \%)$ premature labour, (29\%) prolonged labour, (15.5\%) excessive bleeding, (12.1\%) convulsion and (6.2\%) had breech presentation. Despite the proximity of the hospital to the parturient, most of them laboured in substandard facilities within the community. Referrals to tertiary care centres were made only after prolonged delay and onset of complication.

In present study, all the $7(100 \%)$ unregistered pregnant women received blood transfusion as compared to 10 $(10.5 \%)$ of registered pregnant women. To improve maternal health, barriers that limit access to quality maternal health services must be identified and addressed at all levels of the health system. ${ }^{2}$ Thaker $\mathrm{R}$ et al. ${ }^{2}$ concluded that family members must be made aware of warning signs. Strengthening of primary and secondary level facilities and timely referral to tertiary level can play a crucial role in reducing maternal morbidity and mortality.

\section{Limitations}

Tertiary care centre does not have any catchment area and the study subjects in our study were the patients admitted at our institute, hence data could not represent any particular population, so the result of this study at tertiary care centre cannot be generalised to population. Secondly, data we analysed were from a cross sectional study, hence we could not draw conclusion about causality, which need further studies. Thirdly, we have not analysed correlates like distance of health facility from residence, availability of transport facilities, which could have influenced the outcome of complications in pregnancy.

\section{CONCLUSIONS}

Complication can arise at any time during pregnancy, childbirth and postnatal period and in absence of intervention, there is a high feto-maternal morbidity and mortality. Health education at community level is necessary to create awareness about importance of ante natal care, institutional delivery and post natal care in addition to increasing rate of literacy and women empowerment.

Multidisciplinary team approach along with blood bank facility, intensive care specialist and anaesthesiologists can bring optimal care for mother.

\section{Funding: No funding sources}

Conflict of interest: None declared

Ethical approval: The study was approved by the Institutional Ethics Committee

\section{REFERENCES}

1. Ashwini S, Shivaswany MS, Katti S, Mallapur MD. Profile of Antenatal Women Attending Urban Health Centre, Khasbag, Belgaum. Medica Innovatica. 2012;1(2):43-8.

2. Thaker R, Deliwala K, Jadav MM. Retrospective Comparative Study of Obstetric complications and Maternal Mortality in Registered and Unregistered women at Tertiary Care Hospital. NHL Journal of Medical Sciences. 2013;2(1):28-35.

3. Gogoi M, Unisa S, Prusty R. Utilization of maternal health care services and reproductive health complications in Assam, India. Journal of Public Health. 2014;22(4):351-9. 
4. The World Health Report 2005 - make every mother and child count. World Health Organization;2005.

5. Datta KK, Sharma R.S, Razack P, Ghosh TK, Arora RR. Morbidity pattern amongst rural pregnant women in Alwar, Rajasthan- a cohort study. Health and Population: Perspectives and Issues. 1980;3(4):282-92.

6. Papia R. Pregnancy complications and healthseeking behaviour among married women in Uttar Pradesh, India. Research and Practice in Social Sciences. 2005;1(1):48-63.

7. Matthews M. Reviewing Maternal Deaths and Complications to Make Pregnancy and Childbirth Safe. Regional Health Forum. 2005;9(1).

8. Office of the Registrar General and Census Commissioner (India). India SRS Special Bulletin on Maternal Mortality 2007-2009. New Delhi, India: Office of the Registrar General and Census Commissioner (India).

9. Sugathan KS, Mishra VK, Retherford RD.Promoting institutional deliveries in rural India: the role of antenatal-care services. National family health survey subject reports; 2001.

10. Guidelines for pregnancy care and management of common obstetric complications by medical officers. Maternal Health Division, Department of Family Welfare, Ministry of Health and Family Welfare Government of India;2005.
11. Daftary SN, Chakravarti S. Manual of obstetrics, updated edition of the classic Holland and Brews Manual of obstretics. 3rd edition Elsevier Health Sciences;2011.

12. NFHS-3. National Family Health Survey: http://www.nfhsindia.org. URL: jknrhm.com/Guideline/Normal_delivery_and_manag ement_of obstretic_complication.pdf. accessed on 14 November 2014.

13. Verma V, Das KB. Teenage primigravidae: a comparative study. Indian J Public Health. 1997;41(2):52-5.

14. Kore SJ, Rao S, Bhagwat A, Ishwar G, Vaidyanathan U, Kulkarni VA et al. The challenge of adolescent pregnancies- Experiences at a tertiary referral centre. Indian Medical Gazette. 2004;138(12):502-4.

15. Jat TR, Ng N, San Sebastian M. Factors affecting the use of maternal health services in Madhya Pradesh state of India: a multilevel analysis. Int $\mathbf{J}$ Equity Health. 2011;10:59.

DOI: $10.5455 / 2320-1770 . i j r \operatorname{cog} 20150410$

Cite this article as: Shirpurkar MS, Shewte MK, Joshi PG. Pattern of obstetrics complication among pregnant females admitted in a tertiary care centre in central India. Int J Reprod Contracept Obstet Gynecol 2015;4:338-43. 